\title{
Predição da Potencial Evasão Acadêmica entre Estudantes Trabalhadores e Não Trabalhadores
}

\author{
Rodolfo A. M. Ambiel ${ }^{1, *}$ (D, Pedro Afonso Cortez $^{2}$ (D), \& Ana Paula Salvador ${ }^{1}$ (1) \\ ${ }^{1}$ Universidade São Francisco, Campinas, São Paulo, Brasil \\ ${ }^{2}$ Universidade Metodista de São Paulo, São Bernardo do Campo, São Paulo, Brasil
}

\begin{abstract}
RESUMO - A evasão do ensino superior é um problema relevante. Muitos estudantes não concluem o nível superior devido às dificuldades financeiras e questões psicossociais. Neste contexto, o objetivo do estudo foi identificar preditores dos motivos para a potencial evasão do ensino superior entre 385 estudantes universitários empregados e 397 estudantes desempregados. Os resultados mostraram que os motivos para a potencial evasão do ensino superior na amostra abrangeram os fatores vocacionais, carreira, desempenho acadêmico, interpessoais e falta de suporte. Essas evidências demonstram que a potencial evasão pode ser compreendida por preditores relacionados ao tipo de instituição, financiamento, autoavaliação de desempenho e níveis de satisfação com o curso, condição financeira e escolha profissional. Nas relações de predição entre estudantes que trabalham e não trabalham, há ainda especificidades fundamentais para formular políticas e práticas, com o intuito de maximizar a permanência dos alunos na graduação e otimizar o planejamento da trajetória acadêmica e profissional desses estudantes.
\end{abstract}

PALAVRAS-CHAVE: M-ES, intenção de evasão, trabalho, educação superior

\section{Prediction of Potential Higher Education Dropout in Employed and Unemployed Undergraduate Students}

\begin{abstract}
Higher education dropout is a relevant problem. Many students do not complete college because of financial and psychosocial issues. We aimed to identify predictors of the reasons for potential dropout of higher education among 385 university students employed and 397 unemployed. We showed that the reasons for the potential dropout of higher education in the sample are related to factors as vocational, career, academic performance, interpersonal and lack of support. This evidence demonstrates that predictors related to the type of institution, study financing, self-evaluation and levels of satisfaction with course, financial condition and professional choice predict the college dropout potential among students who work and do not work. Thus, it is necessary to plan public policies that cover these variables and consider the specificities of these groups while formulating policies and practices with the purpose of maximizing student's permanence in higher education and optimizing their professional trajectory planning.
\end{abstract}

KEYWORDS: M-ES, dropout intention, labor, higher education

Estatísticas nacionais indicam que o aumento no número de matrículas no nível superior brasileiro segue em razoável expansão anualmente, sugerindo um crescente acesso ao nível superior (Gomes \& Moraes, 2012; MEC, 2015; INEP, 2000, 2015). Essa expansão resulta em desafios causados pela ineficácia das políticas públicas brasileiras que garantam a permanência aos estudantes no nível superior (Arruda \& Gomes, 2015; Almeida, 2007; Amaral \& Oliveira,
2011; Bardagi \& Hutz, 2014; Mancebo et al., 2015; Queiroz et al., 2013).

Nesse cenário, cerca de $25 \%$ dos estudantes não concluem o nível superior (Carmo et al., 2014; MEC, 2015). A diferença entre o número de alunos que ingressam e não concluem é denominado evasão do ensino superior (SEMESP, 2016; Silva, et al., 2007; Sneyers \& De'Witte, 2017). Esse fenômeno resulta em prejuízos aos indivíduos

* E-mail: ambielram@gmail.com
- Submetido: 10/01/2018; Aceito: 07/11/2018. 
e às instituições educacionais (Sehnem \& Campos, 2015; Silva \& Sauaia, 2014; Silva et al., 2007). Os dados mais recentes indicam $27,9 \%$ de evasão na rede privada e $18,3 \%$ na pública (SEMESP, 2016), sendo maior nos primeiros períodos por inconsistências no financiamento estudantil (Cardak \& Vecci, 2015) e menor entre alunos que contam com financiamento governamental em períodos posteriores (Silva, 2013).

Internacionalmente, notam-se dificuldades semelhantes na evasão no ensino superior. Para lidar com o problema, algumas investigações demonstram a eficácia de políticas de financiamento estudantil (Boatman \& Long, 2016; Carvalho, 2006). Outros estudos indicam a importância de se explorar outras variáveis ao tratar da evasão no ensino superior, como a insatisfação com a qualidade de ensino, a responsabilidade pela família, a sobrecarga de trabalho, as dificuldades financeiras ou a protelação da formatura (Cunha et al., 2015; Gairín et al., 2014; Silva, 2013). Cabe salientar que enfatizando a evasão por aspectos socioeconômicos, esse fenômeno acontece principalmente entre estratos sociais mais vulneráveis (Baggi \& Lopes, 2011; Cassundé et al., 2015; Graf \& Diogo, 2009; Souza et al., 2016), devido às constantes dívidas e exigências relacionadas à subsistência do estudante (Ribeiro, 2005; Santos et al., 2015; Silva \& Teixeira, 2013; Stinebrickner \& Stinebrickner, 2014; Zago et al., 2016).

Além das questões socioeconômicas, outros elementos relevantes para apreender adequadamente a evasão do ensino superior são as variáveis psicossociais. Destacam-se entre elas, a percepção do indivíduo sobre a qualidade do nível superior, que também impacta na evasão (Croxton, 2014). Também se mostram importantes crenças, níveis de satisfação, entre outras percepções individuais que se apresentem como cognições avaliativas do acadêmico sobre si mesmo e o ambiente universitário (Jorgensen et al., 2012). Neste sentido, é importante investigá-las, pois essas variáveis tendem a predizer a evasão no nível superior (Duque, 2014; Duque et al., 2013; Schlesinger et al., 2016), sendo útil para a proposição de evidências que busquem facilitar a permanência acadêmica do estudante na universidade (Almeida et al., 2015; Bacelar-Nicolau et al., 2015; Bardagi \& Hutz, 2012; Hagenauer \& Volet, 2014).

Na literatura, a evasão do ensino superior é uma proposta compreendida como um campo de investigação plural, o qual tende a apreender a questão por meio de fatores psicológicos que se relacionam à intenção de evasão ou indicadores e estatísticas oficiais que expressam o nível de evasão de determinada instituição ou país (Aljohani, 2016; Duque, 2014; Eicher et al., 2014; Heublein, 2014). No presente estudo, enfatiza-se a primeira perspectiva, por meio dos motivos para evasão do ensino superior, cujos fatores se mostram predominantemente psicológicos (Ambiel, 2016). Para tanto, busca-se compreender os conteúdos que energizam a potencial decisão de o indivíduo deixar o ensino superior.
O potencial de evasão diferencia-se da intenção comportamental, pois associa-se de forma imediata aos motivos para evasão do ensino superior que, a posteriori, podem ou não resultar na intenção de evasão do ensino superior (Ambiel, 2015). Salienta-se que os motivos para evasão do ensino superior avaliados no presente estudo foram inspirados nas formulações de Tinto (1975), as quais compreendem a potencial evasão como complexa e multideterminada. Em síntese, a influência simultânea dos motivos para evasão apreendidos pelo estudante potencializa a possibilidade de o indivíduo intencionar evadir e, por conseguinte, no comportamento do acadêmico de permanecer ou abandonar o nível superior (Heublein, 2014; Spady, 1970).

Dessa forma, pautando-se na compreensão de que fatores socioeconômicos e psicológicos influenciam na evasão do ensino superior, almejou-se compreender no presente estudo o impacto de instituições públicas vs. privadas, ser beneficiário de bolsa escolar, financiar o próprio o estudo, estudar à noite, estar satisfeito com o curso, condição financeira e escolha profissional e a própria autoavaliação (McKinney, Burridge, 2015; Rodríguez-Gómez et al., 2015; Sneyers \& De'Witte, 2017; Strahan \& Credé, 2015) nos motivos para potencial evasão do ensino superior de estudantes que trabalham e dos que não trabalham. Fez-se a opção por segmentar a amostra nesses dois grupos, pois esse critério mostra-se relevante para diferenciar estudantes com condições socioeconômicas distintas e, portanto, passível de apreender preditores que agem de formas distintas nos dois públicos (Oliveira, 2018).

Destaca-se que a segmentação do público-chave da investigação em termos funcionais (trabalhar vs. não trabalhar) em vez de indicadores puramente socioeconômicos aconteceu pela compreensão de que as predições se tornam mais úteis à formulação de políticas e intervenções quando favorecem categorias com maior facilidade de distinção cotidiana quando comparadas àquelas abstratas, tal como ocorre comumente com critérios de estratificação socioeconômica (Braveman et al., 2005). Por exemplo, as pessoas podem facilmente se identificar como vinculadas ao trabalho ou não, mas não necessariamente conseguirem relatar sobre o estrato socioeconômico a que pertencem (B, C, D, etc.). No momento presente, essa distinção é fundamental, pois a crescente precarização social de diferentes práticas, incluindo o campo do trabalho, com a terceirização de atividades-fim e fragilização dos vínculos trabalhistas, torna a inserção dos estudantes no mundo laboral precoce e precarizada, o que tende a interferir na trajetória estudantil e se afirma um tema central para análise (Borges, 2017; Correia, 2017; Oliveira, 2018).

No escopo da presente investigação, a compreensão das características socioeconômicas e atributos pessoais relacionados aos motivos para potencial evasão no ensino superior entre trabalhadores e não trabalhadores pode 
facilitar o delineamento de políticas públicas e ações institucionais favoráveis à permanência desses grupos no espaço acadêmico ao compreender preditores específicos da potencial evasão entre esses estudantes (Ambiel et al., 2016; Bardagi \& Hutz, 2014; Bisinoto \& Marinho-Araújo,
2014; Zago, 2006). Assim, pelos aspectos supracitados e considerando-se a necessidade de se aprofundar na compreensão do tema, objetivou-se identificar preditores dos motivos para a potencial evasão do ensino superior entre estudantes trabalhadores e não trabalhadores.

\section{MÉTODO}

\section{Participantes}

Participaram da pesquisa 782 estudantes universitários de instituições públicas $(24,5 \%)$ e privadas $(75,5 \%)$ de ensino superior de todas as regiões brasileiras (Sudeste $=45 \%$; $\mathrm{Sul}=30 \%$; Nordeste $=17 \%$; Centro-Oeste $=5 \%$; Norte $=$ $3 \%$ ), sendo $53,9 \%$ de homens e $46,1 \%$ de mulheres. A idade média foi 23,6 anos $(D P=7,31)$. A maioria financiava o próprio estudo $(64,4 \%)$ ou contava com o financiamento por terceiro ou bolsa $(35,6 \%)$, tinha renda mensal entre 2 e 6 salários mínimos $(74,2 \%)$ ou recebia até 1,5 salário mínimo $(14,0 \%)$ e cursava no período noturno $(69,4 \%)$, sendo que $49,2 \%$ trabalhavam e $50,8 \%$ não trabalhavam. Em média, os estudantes cursavam a graduação há 2 anos e meio $(D P=1,22)$.

\section{Instrumentos}

\section{Escala de Motivos para Evasão do Ensino Superior (M-ES)}

Essa escala é um instrumento de autorrelato com 53 itens, sendo empregada escala de respostas do tipo Likert com cinco pontos $(1=$ Muito Fraco $; 5=$ Muito Forte $)$. Apresenta estudos anteriores indicando evidências de validade quanto à estrutura interna no contexto brasileiro (Ambiel, 2015, 2016). A consistência interna foi estimada no presente estudo por meio do $\lambda_{6}$ de Guttman, o qual se mostrou adequado, variando entre $\lambda_{6}=0,72 \sim 0,91$, para os fatores da medida. No preenchimento, o estudante é instruído a assinalar até que ponto cada um dos motivos elencados é capaz de influenciar a decisão de deixar ou parar o curso superior frequentado pelo acadêmico.

Neste instrumento, os motivos para potencial evasão do ensino superior são analisados por meio de sete fatores: 1) institucionais (estrutura, serviços e relações institucionais); 2) falta de suporte (dificuldades financeiras e conflitos família/trabalho); 3 ) vocacionais (escolha do curso e permanência por interesse profissional); 4) desempenho (notas, reprovações e proficiência no conteúdo); 5) interpessoais (relacionamento com pares próximos); 6) carreira (perspectiva de futuro profissional); 7) autonomia (responsabilidades e exigências acadêmicas e domésticas). De forma conjunta, esses fatores caracterizam motivos que abrangem conteúdos capazes de influenciar a potencial evasão estudantil do nível superior.

\section{Procedimentos}

O protocolo de pesquisa foi submetido ao Comitê de Ética em Pesquisa com Seres Humanos da instituição propositora da investigação, obtendo parecer favorável por meio do CAAE: 21887613.7.0000.5514 e demonstrando conformidade com os regulamentos brasileiros para pesquisas não identificadas com seres humanos (CNS, 2016). Os dados foram coletados presencialmente $(n=$ $267)$ e on-line $(n=515)$. Nas duas formas de aplicação, foram realizados contatos prévios com as coordenações de curso das diferentes instituições participantes, a fim de operacionalizar formas viáveis para a participação dos estudantes. No procedimento presencial, a coleta foi realizada de forma coletiva em sala de aula com uso de lápis e papel por um psicólogo da equipe executora. Na versão on-line, a coordenação de curso disparava um e-mail com uma carta convite redigida pelos pesquisadores, o qual continha instruções e um link para participação na pesquisa, sendo o sistema adaptativo para diagramação em telas de computadores, celulares e outros gadgets.

\section{Análise dos dados}

Os dados foram analisados com SPSS (Statistical Package for the Social Sciences) versão 18 e JASP versão 0.8.8.1. No SPSS foi realizada a análise exploratória, inspeção do banco de dados, estatísticas descritivas e gerados os modelos de regressão. O software JASP foi empregado para cálculo do $\lambda 6$ de Guttman. No procedimento de inspeção, adequaram-se os erros de digitação e verificouse a normalidade na distribuição por meio dos índices de assimetria e curtose, os quais resultaram na exclusão daqueles outliers com valores superiores a $|2,0|$ (Miles \& Shelvin, 2001; Pasquali, 2015).

As estatísticas descritivas foram empregadas para caracterizar a amostra em relação a M-ES e segmentar os estudantes em dois grupos utilizados para as análises, sendo trabalhadores $(n=385)$ e não trabalhadores $(n=397)$. Os modelos de regressão gerados utilizaram o método enter, sendo as variáveis lançadas simultaneamente em um único bloco (Hair et al., 2009). O teste de Durbin Watson foi empregado para analisar a adequação dos resíduos (Fávero \& Fávero, 2016). O $\lambda 6$ de Guttman foi aplicado para verificar a consistência interna dos fatores da M-ES (Guttman, 1945). 


\section{RESULTADOS}

Os modelos preditivos gerados para explicação dos motivos para a potencial evasão do ensino superior para os fatores vocacionais, interpessoais, falta de suporte, carreira, e desempenho acadêmico mostraram-se significativos para os dois grupos. No entanto, as propostas preditivas realizadas para os fatores institucionais e autonomia não foram significativas para a explicação do fenômeno na amostra. As variáveis preditoras mostraram-se diversas entre os diferentes fatores relacionados aos motivos para potencial evasão do ensino superior. Em todos os modelos propostos, os resíduos se mostraram adequados, tendo em vista que os valores ficaram próximos a 2,0 no teste de Durbin Watson.

Os maiores percentuais de variância explicada $\left(\mathrm{R}^{2}\right)$ para o conjunto de variáveis elencados foram propostos para os fatores relacionados à carreira, vocacionais e desempenho acadêmico com $\mathrm{R}^{2}$ variando entre $6,6 \%$ e $12,9 \%$. Os fatores interpessoais e falta de suporte também se mostraram significativos com percentual moderado de variância explicada $\left(\mathrm{R}^{2}\right)$, o qual oscilou entre $5,4 \%$ e $6,6 \%$. Os fatores institucionais e autonomia não foram significativos e obtiveram menores percentuais de variância explicada $\left(R^{2}\right)$ com índices entre $1,6 \%$ e 3,7\% nos modelos investigados. Na Tabela 1 apresenta-se uma síntese dos modelos de predição.

O preditor instituição particular reduziu os motivos para potencial evasão relacionados aos fatores vocacionais e desempenho acadêmico entre os estudantes que não trabalhavam. Essa variável também diminuiu os motivos para a potencial evasão ocasionados pelo fator carreira nos dois grupos de estudantes. O financiamento próprio dos estudos aumentou entre universitários trabalhadores os motivos para a potencial evasão desencadeados pelo fator falta de suporte. A autoavaliação minimizou os motivos para potencial evasão ocasionados pelos fatores interpessoais, falta de suporte e desempenho acadêmico entre estudantes trabalhadores.

Os níveis de satisfação do estudante também impactaram nos motivos para a potencial evasão. A satisfação com o curso reduziu a potencial evasão gerada por motivos relacionados aos fatores institucionais nos dois grupos e fatores interpessoais e carreira entre não trabalhadores. A satisfação financeira diminuiu os motivos para a potencial evasão pelos fatores institucionais, falta de suporte e interpessoais em universitários que não trabalhavam. A satisfação com a escolha profissional minimizou os motivos para potencial evasão gerados pelos fatores vocacionais nos dois grupos e pelo fator carreira entre estudantes que trabalhavam. Por sua vez, as variáveis renda, bolsa para financiamento dos estudos e período do dia em que o universitário estuda não se mostraram significativos na predição dos motivos para potencial evasão do ensino superior.

Tabela 1

Impacto dos preditores nos motivos para potencial evasão do ensino superior

\begin{tabular}{|c|c|c|c|c|c|c|c|c|c|c|c|c|c|c|}
\hline \multirow{3}{*}{$\begin{array}{l}\text { Descrição das } \\
\text { variáveis }\end{array}$} & \multirow{2}{*}{\multicolumn{2}{|c|}{$\begin{array}{c}\text { Institucionais } \\
\boldsymbol{\beta} \\
\end{array}$}} & \multirow{2}{*}{\multicolumn{2}{|c|}{$\begin{array}{c}\text { Vocacionais } \\
\beta \\
\end{array}$}} & \multirow{2}{*}{\multicolumn{2}{|c|}{$\begin{array}{c}\text { Falta de } \\
\text { Suporte }\end{array}$}} & \multirow{2}{*}{\multicolumn{2}{|c|}{$\begin{array}{c}\text { Carreira } \\
\boldsymbol{\beta} \\
\end{array}$}} & \multirow{2}{*}{\multicolumn{2}{|c|}{$\begin{array}{c}\text { Desempenho } \\
\text { Acadêmico }\end{array}$}} & \multirow{2}{*}{\multicolumn{2}{|c|}{$\begin{array}{c}\text { Interpessoais } \\
\beta \\
\end{array}$}} & \multirow{2}{*}{\multicolumn{2}{|c|}{$\begin{array}{c}\text { Autonomia } \\
\boldsymbol{\beta} \\
\end{array}$}} \\
\hline & & & & & & & & & & & & & & \\
\hline & $\mathbf{T}$ & NT & $\mathbf{T}$ & NT & $\mathbf{T}$ & NT & $\mathbf{T}$ & NT & $\mathbf{T}$ & NT & $\mathbf{T}$ & NT & $\mathbf{T}$ & NT \\
\hline Intercepto & 33,26 & 30,68 & 32,91 & 36,07 & 37,64 & 36,34 & 21,67 & 24,80 & 23,70 & 24,63 & 21,44 & 17,61 & 11,89 & 11,77 \\
\hline $\begin{array}{l}\text { Instituição } \\
\text { particular }\end{array}$ & 0,02 & 0,08 & $-0,10$ & $-0,27 * *$ & 0,04 & $-0,08$ & $-0,12 *$ & $-0,20 * *$ & $-0,01$ & $-0,10^{*}$ & $-0,05$ & $-0,08$ & 0,03 & $-0,06$ \\
\hline Bolsista & $-0,03$ & $-0,07$ & 0,09 & 0,04 & $-0,09$ & $-0,04$ & 0,02 & $-0,01$ & $-0,06$ & 0,06 & $-0,07$ & $-0,01$ & 0,01 & 0,04 \\
\hline Financiamento & 0,08 & 0,00 & $-0,01$ & $-0,06$ & $0,13^{* *}$ & 0,00 & $-0,02$ & $-0,01$ & 0,02 & $-0,04$ & 0,01 & 0,03 & 0,08 & 0,01 \\
\hline Noturno & $-0,01$ & $-0,04$ & 0,00 & $-0,07$ & $-0,01$ & $-0,09$ & $-0,02$ & $-0,07$ & 0,01 & $-0,07$ & $-0,05$ & $-0,07$ & $-0,08$ & $-0,03$ \\
\hline Autoavaliação & $-0,05$ & 0,02 & 0,00 & 0,03 & $-0,13^{*}$ & 0,04 & 0,04 & $-0,08$ & $-0,27 * *$ & $-0,08$ & $-0,12 *$ & $-0,01$ & $-0,03$ & 0,05 \\
\hline $\begin{array}{l}\text { Satisfação } \\
\text { Curso }\end{array}$ & $-0,15 * *$ & $-0,11 *$ & $-0,08$ & $-0,05$ & 0,10 & $-0,10$ & $-0,02$ & $-0,18 * *$ & 0,04 & $-0,07$ & $-0,09$ & $-0,12 *$ & 0,00 & $-0,09$ \\
\hline $\begin{array}{l}\text { Satisfação } \\
\text { Financeira }\end{array}$ & 0,01 & $-0,11 *$ & 0,08 & $-0,04$ & $-0,01$ & $-0,18 * *$ & 0,01 & & $-0,03$ & $-0,09$ & 0,00 & $-0,11 *$ & 0,05 & $-0,08$ \\
\hline $\begin{array}{l}\text { Satisfação } \\
\text { escolha } \\
\text { profissional }\end{array}$ & $-0,01$ & 0,05 & $-0,24 * *$ & $-0,13 * *$ & $-0,07$ & 0,06 & $-0,25 * *$ & $-0,08$ & $-0,07$ & $-0,07$ & $-0,07$ & 0,03 & 0,02 & 0,04 \\
\hline Renda & 0,04 & 0,02 & 0,02 & 0,03 & $-0,06$ & $-0,02$ & 0,05 & 0,02 & 0,04 & 0,02 & 0,01 & 0,06 & $-0,05$ & $-0,03$ \\
\hline $\mathrm{R}^{2}$ & $3,5 \%$ & $3,7 \%$ & $8,5 \%$ & $12,9 \%$ & $5,5 \%$ & $6,6 \%$ & $8,5 \%$ & $12,3 \%$ & $9,6 \%$ & $6,6 \%$ & $5,8 \%$ & $5,4 \%$ & $1,6 \%$ & $2,4 \%$ \\
\hline $\mathrm{F}$ & 1,52 & 1,62 & 3,89 & 6,35 & 2,42 & 3,04 & 3,86 & 6,05 & 4,40 & 3,01 & 2,56 & 2,47 & 0,68 & 1,05 \\
\hline Durbin-Watson & 2,04 & 2,06 & 2,00 & 2,04 & 1,98 & 1,97 & 2,01 & 1,96 & 1,75 & 1,93 & 1,95 & 1,97 & 2,07 & 2,05 \\
\hline Model p.value & $\mathrm{p}>0,05$ & $\mathrm{p}>0,05$ & $\mathrm{p}<0,01$ & $\mathrm{p}<0,01$ & $\mathrm{p}<0,01$ & $\mathrm{p}<0,01$ & $\mathrm{p}<0,01$ & $\mathrm{p}<0,01$ & $\mathrm{p}<0,01$ & $\mathrm{p}<0,01$ & $\mathrm{p}<0,01$ & $\mathrm{p}<0,01$ & $\mathrm{p}>0,05$ & $\mathrm{p}>0,05$ \\
\hline
\end{tabular}

Nota. $\beta=$ Coeficiente Beta Padronizado, $T=$ Trabalhadores, NT=Não trabalhadores, Nível de significância $*=\leq 0,05^{* *}=\leq 0,01$ 


\section{DISCUSSÃo}

O presente estudo objetivou identificar preditores dos motivos para a potencial evasão do ensino superior entre estudantes trabalhadores e não trabalhadores. Pelas evidências geradas pelos modelos propostos, os diferentes preditores foram importantes para predizer motivos para a potencial evasão ocasionados pelos fatores vocacionais, interpessoais, falta de suporte, carreira, desempenho acadêmico. As relações de predição pelas variáveis elencadas no estudo se mostraram parcialmente distintas entre trabalhadores e não trabalhadores, sendo abordadas pontualmente adiante.

Vincular-se às instituições particulares reduz a potencial evasão desencadeada pelo fator carreira nos dois grupos, o que pode ser explicado pela maior ênfase dessas instituições na atuação profissional a ser desempenhada pelo estudante, diminuindo os motivos para potencial evasão pelo fator carreira. No grupo de não trabalhadores, a maior disponibilidade de vagas nessas instituições particulares, que favorece a inserção do estudante no curso de interesse quando comparadas com universidades públicas, e as avaliações de recuperação típicas em particulares, diminuem os motivos para a potencial evasão gerados, respectivamente, pelos fatores vocacionais e desempenho acadêmico.

Isso acontece pois as instituições particulares brasileiras priorizam estágios e outras atividades profissionais voltadas à inserção do aluno no contexto do trabalho (Cassundé et al., 2015). As instituições públicas brasileiras de nível superior, por sua vez, incentivam programas voltados para aspectos sociais e científico, como extensão e pesquisa (Sguissardi, 2005). Essa dicotomia entre ambiente acadêmico e mercado de trabalho existente nas instituições de nível superior públicas e privadas parece distanciar o universitário das oportunidades de inserção no mercado privado, o que pode resultar na menor percepção de empregabilidade e carreiras fora da universidade em estudantes de instituições públicas, explicando as diferenças encontradas nos preditores supracitados. Neste sentido, aumentar a ênfase entre formação acadêmica e atividade profissional, permitir que o estudante ingresse no curso de interesse e propiciar condições para recuperar as notas se mostram como estratégias a serem exploradas para diminuir a potencial evasão associado aos fatores interpessoais, carreira e desempenho acadêmico no âmbito das instituições de nível superior.

A relação existente entre financiamento próprio do curso e os motivos para potencial evasão pelo fator falta de suporte entre estudantes que trabalham demonstra que é provável uma maior vulnerabilidade social neste grupo, o que pode indicar dificuldade de conciliar estudo-trabalho e, consequentemente, resultar na menor percepção de suporte. Tal questão pode ainda afetar o desempenho do aluno trabalhador e, consequentemente, levá-lo a optar pela potencial evasão devido à falta de suporte, uma vez que as dificuldades financeiras maximizam a potencial evasão, devido às dificuldades do estudante se manter inserido no meio acadêmico (Souza et al., 2016). No caso de estudantes que não trabalhavam, a própria fonte de financiamento do estudo não se mostra relevante.

Assim, para enfrentar a potencial evasão por questões socioeconômicas, políticas públicas que favoreçam o suporte social e econômico de estudantes que trabalham se fazem importantes. Incluem-se entre elas aquelas que favoreçam a permanência nas universidades públicas ou possibilitem a gratuidade e financiamento nas universidades privadas. No geral, essas ações maximizam o suporte socioeconômico prestado ao estudante e, portanto, se mostram relevantes para impactar no menor potencial de evasão pelo fator falta de suporte. Outra questão crucial é a instauração de políticas públicas capazes de incentivar as empresas brasileiras a criar vagas que adequem o horário de trabalho às necessidades dos estudantes, para, assim, minimizar os motivos para potencial evasão relacionados à falta de suporte. Reitera-se que, apesar de ideal, essa proposta se mostra atualmente inviável em empresas privadas pela crescente precarização social do trabalho (Oliveira, 2018), mas passível de implementação em empresas públicas. Por esse motivo, anterior à proposta de carga horária compatível, é preciso que financiamentos e subsídios sejam prestados às organizações privadas que facilitam a inserção do estudante trabalhador no nível superior, com o intuito de viabilizar a jornada compatível entre trabalho e estudo para os estudantes que trabalham.

O fato de a autoavaliação do estudante diminuir a potencial evasão demonstra que os acadêmicos que trabalham utilizam da autocrítica como forma de julgar sobre a possível permanência ou evasão do curso ao passo que estudantes que não trabalham não têm a potencial evasão impactada por essa variável. Os estudantes que trabalham e fazem uma pior autoavaliação sobre o desempenho acadêmico tendem a maximizar o potencial de evasão pelos fatores interpessoais, falta de suporte e desempenho. Sobre a dinâmica existente entre esses fatores, é possível inferir que entre estudantes trabalhadores a ausência de suporte prejudique o desempenho do aluno e, consequentemente, fragilize as relações acadêmicas interpessoais pelo aluno não conseguir acompanhar a turma, o que reduz o contato com colegas e maximiza os motivos para a potencial evasão por questões interpessoais (Santos et al., 2015). Em relação ao efeito da autoavaliação para a potencial evasão entre estudantes trabalhadores, essa evidência indica que os estudantes que trabalham demonstram mais preocupação com o próprio desempenho e seus impactos na trajetória acadêmica e profissional.

No presente modelo, hipotetiza-se que essa dinâmica sugere maior lócus de controle interno entre estudantes que trabalham quando comparados aos que não trabalham. No entanto, sugere-se que tal processo seja investigado para verificar o efeito do trabalho ao longo da graduação na 
atribuição de causalidade individual pessoal e acadêmica, com o intuito de controlar o efeito gerado por essa variável na potencial evasão estudantil (D'Lima et al., 2014). Especificamente, é preciso compreender qualitativamente como as demandas relativas à jornada de trabalho e ao meio acadêmico acontecem, de forma processual, para se apurar de que forma a autoavaliação realizada por esses acadêmicos incide na potencial evasão. Os estudantes que se avaliam negativamente e tendem à potencial evasão o fazem pela impossibilidade de conciliar a jornada de trabalho com os estudos ou existem outras influências psicossociais que incidem sobre a questão? Compreender quais condições de trabalho e características psicossociais se mostram presentes entre estudantes que trabalham, se avaliam positivamente no ambiente acadêmico e possuem baixos índices de potencial evasão também pode sugerir caminhos para se compreender o tema com maiores detalhes.

A despeito da ausência de detalhes sobre o efeito da autoavaliação, nota-se que, de forma geral, os vínculos precarizados com colegas e o nível de aproveitamento do curso que o aluno percebe podem aumentar a potencial evasão entre aqueles que trabalham. Por essa razão, esse grupo deve ser foco de práticas, cujas estratégias integrem a vulnerabilidade social do estudante que trabalha ao desempenho acadêmico e relações interpessoais. Tal demanda, torna emergente a necessidade de que intervenções sobre o tema com este público integrem outros pares inseridos no ambiente acadêmico, com o intuito de maximizar o suporte percebido, bem como favorecer relações interpessoais que facilitem a inclusão e a otimização do desempenho do aluno para impactar em menor potencial de evasão desencadeado por esses fatores.

O efeito do nível de satisfação com o curso e a potencial evasão desencadeada pelo fator institucional nos dois grupos revela o papel central das expectativas frente ao curso na compreensão desse fenômeno. Infere-se que uma maior satisfação com o curso diminua os motivos para potencial evasão gerados pelo fator institucional, pois o estudante encontra condições formativas que favoreçam o desenvolvimento e a permanência na instituição de nível superior. No entanto, no caso dos estudantes que não trabalham, além das expectativas formativas associadas ao fator institucional, a potencial evasão associada à satisfação com curso e desencadeada pelos fatores interpessoais e carreira demonstra que esses alunos também associam a possível evasão ao quanto o curso se adequa às expectativas de carreira e à qualidade dos vínculos no espaço acadêmico.

Sobre essa dinâmica, cabe destacar que não trabalhar garante ao aluno mais tempo no ambiente acadêmico e na interação com colegas, o que torna a satisfação com o curso atrelada aos relacionamentos associada ao convívio com os pares acadêmicos e, consequentemente, capaz de influenciar os motivos para potencial evasão por razões interpessoais (Bardagi \& Hutz, 2012) entre estudantes não trabalhadores. Por essa razão, faz-se necessário fortalecer as condições institucionais para atender às expectativas de formação dos alunos, o que perpassa por considerar de que forma as relações e condições institucionais podem ser úteis para impulsionar a trajetória profissional dos estudantes. Esses aspectos se mostram centrais para favorecer a potencial permanência dos estudantes no nível superior, ressaltandose a importância de abranger com maior especificidade os vínculos com os pares acadêmicos ao tratar da questão com estudantes que não trabalham.

Ainda sobre a satisfação, mas focando-se o aspecto financeiro, a satisfação do aluno com a própria condição econômica não se mostra relevante entre universitários que trabalham, mas se apresenta como uma variável importante para compreender a potencial evasão entre estudantes que não trabalham ao se analisar os fatores institucionais, interpessoais e falta de suporte. É provável que, com menor nível de satisfação financeira, o estudante que não trabalha vislumbre um potencial de evasão por fatores institucionais pela dificuldade de arcar com as exigências de materiais e outros custos necessários para a inserção acadêmica demandados pela instituição de nível superior. Desse modo, é possível inferir que esse estudante que não trabalha dependa do núcleo familiar ou do financiamento estudantil para se manter no meio acadêmico. Assim, nos casos em que a família não consegue arcar com os custos e as políticas de financiamento se mostram insuficientes é provável que o estudante relate insatisfação com a própria condição financeira, percebendo motivos para a potencial evasão pela falta de suporte (Ribeiro, 2005).

Ainda, o potencial de evasão gerada pelos fatores interpessoais e falta de suporte dificulta o relacionamento cotidiano do estudante, uma vez que há ausência de meios para dar conta das demandas financeiras de inserção no nível superior. É possível hipotetizar que o universitário enfrente dificuldades no relacionamento com colegas pela falta de recursos para acompanhá-los no convívio acadêmico. No caso dos familiares, a dificuldade se apresenta por não poderem fornecer o apoio necessário para assegurar a inclusão do estudante. Neste aspecto, reitera-se a necessidade de políticas de financiamento e inclusão no nível superior, que também abranjam estudantes que não trabalham e dependem de familiares para se manter no meio acadêmico, uma vez que na falta de suporte familiar as políticas de financiamento também se mostram relevantes para minimizar a potencial evasão nesse grupo.

Além disso, é fundamental promover orientação vocacional entre estudantes que trabalham e não trabalham, uma vez que maiores níveis de satisfação com a escolha profissional atuam como fator protetivo contra a potencial evasão por fatores vocacionais (Sneyers \& De’Witte, 2017). No caso de estudantes trabalhadores, articular a orientação vocacional à profissão em exercício pode se apresentar como uma demanda específica deste grupo. Isso acontece, pois, o nível de satisfação com a escolha profissional entre estudantes que trabalham se associa aos motivos para 
evasão desencadeados pelo fator carreira, o que acrescenta a necessidade de atuar neste grupo com maior ênfase nas possibilidades de desenvolvimento profissional da atividade laboral em exercício para reduzir a potencial evasão desses estudantes. Ademais, assegurar o ingresso do estudante no curso mais compatível com suas aspirações e interesses também se mostra como um mecanismo relevante para reduzir os motivos para potencial evasão ocasionados por esse fator, demonstrando a centralidade das ações de orientação profissional anterior ao ingresso no curso superior (Gomes \& Moraes, 2012; Queiroz et al., 2013).

Baseando-se nas diferenças e particularidades nos preditores encontradas até então, propõem-se algumas considerações com predominância prática, visando maior aplicação na promoção de condições que incidam em menor potencial de evasão pelos fatores de motivos analisados no presente estudo. Em termos gerais, são necessárias amplas políticas de financiamento do ensino superior para minimizar a potencial evasão pelo fator falta de suporte. Essas ações devem fornecer as mensalidades das instituições particulares ou o ensino público gratuito, assim como propiciar meios para subsistência por meio de bolsas sociais ou parcerias público-privadas para facilitar a permanência estudantil. A contraprestação de serviço pelo estudante em jornada de trabalho compatível com a exigência acadêmica também pode ser uma alternativa a ser delineada entre políticas sociais sobre o tema (Carvalho, 2006).

No que tange à potencial evasão desencadeada pelos fatores vocacionais e carreira, faz-se preciso que ações de orientação profissional aconteçam em momento anterior ao ingresso no ensino superior, uma vez que, após o ingresso, tanto as instituições quanto o sujeito sofrerão prejuízos resultantes da evasão ou transferência de curso (Sehnem \& Campos, 2015). A realização da orientação profissional é fundamental, pois, a médio prazo, pode tornar a escolha do curso superior compatível com os interesses pessoais e de carreira do sujeito, reduzindo a potencial evasão por motivos de carreira e vocacionais (Bardagi \& Hutz, 2014). A implementação da orientação profissional para o nível superior poderia ocorrer com a vinculação dessas práticas às linhas de financiamento ou exames admissionais para ingresso na graduação, o que poderia minimizar a potencial evasão motivada pelos fatores vocacionais e carreira.

Ressalta-se ainda que a identificação do perfil sociodemográfico e o planejamento prévio no que tange ao tempo, fonte de financiamento e recursos investidos no ensino superior também deve integrar o processo de orientação profissional para ingresso no ensino superior (Ribeiro, 2005). Tal dinâmica implica no fato de que reconhecer a realidade concreta é o primeiro passo para planejar caminhos que possibilitem melhores alternativas aos estudantes e, consequentemente, resultem em maior percepção de suporte ao longo do curso com o intuito de diminuir a potencial evasão do ensino superior.
Para minimizar a potencial evasão ocasionada por motivos institucionais, o fortalecimento das comissões avaliativas pode se mostrar como um recurso potente no sentido de padronizar os critérios das práticas educativas frente às expectativas estudantis e padrões de qualidade definidos nas diretrizes nacionais para os cursos de nível superior (Arruda \& Gomes, 2015). Afinal, somente com uma comissão de avaliação do ensino superior atuante, os relatórios anuais de avaliação institucionais poderão ser implementados em ações concretas que impactem na redução da potencial evasão por motivos institucionais que impactam percepção do aluno para permanecer ou planejar evadir do ensino superior por aspectos atrelados à organização escolar (Baggi \& Lopes, 2011).

Visando reduzir a potencial evasão relacionada ao fator desempenho acadêmico é importante que a instituição desenvolva uma compreensão processual ao avaliar o estudante tornando-a formativa, em vez de punitiva (Bisinoto \& Marinho-Araújo, 2014). Essa mudança no paradigma de avaliação, além de otimizar aspectos associados à potencial evasão, pode servir para orientá-lo na superação das dificuldades relacionadas ao conteúdo do curso. Ressalta-se que, no modelo de avaliação como punição, tanto as instituições quanto os alunos perdem, dado que constantes experiências de fracasso reduzem a autoeficácia do estudante motivando a potencial evasão por desempenho insatisfatório (D’Lima et al., 2014).

Por fim, faz-se mister caracterizar as diferentes propostas elencadas para reduzir a potencial evasão estudantil no ensino superior em função daquelas variáveis que se mostraram significativas entre os grupos analisados com base nos modelos gerados. A síntese dessas informações é apresentada por meio da Tabela 2, em que as variáveis significativas na compreensão dos fatores de motivos relacionados à potencial evasão entre estudantes trabalhadores e não trabalhadores são elencados com o intuito de favorecer investigações e intervenções propostas ao tema.

Em relação às limitações do presente estudo, destacase que o baixo número de sujeitos da amostra relativos às regiões Norte e Nordeste pode prejudicar a replicação do modelo ao se enfatizar essas regiões, o que pode ser investigado em exames futuros. Nesse sentido, fazem-se necessários estudos que busquem apreender a potencial evasão entre estudantes das diferentes regiões brasileiras por meio de recortes populacionais específicos, bem como pesquisas posteriores que agreguem aos preditores relatados no presente estudo novas informações para a compreensão da potencial evasão estudantil.

Ademais, outras variáveis que não foram investigadas nos modelos propostos podem ser úteis para expandir as compreensões sobre o tema ao versar sobre estudantes que trabalham e não trabalham, como: a) horas semanais dedicadas às atividades universitárias e trabalho; b) percepção de autoeficácia sobre a capacidade de conciliar trabalho-estudo; c) trabalhar na área de formação; d) 
intenção de atuar na área e e) fase em que se encontra no curso (início, meio e fim). A análise dessas variáveis pode favorecer uma maior compreensão sobre o tema em agendas futuras de investigação, sendo fundamental explorá-las, pois as evidências obtidas nos modelos testados demonstram que compreender a potencial evasão do ensino superior se mostra como uma atividade complexa e multideterminada.

É preciso ressaltar também que a maior parte das propostas supracitadas para diminuir a potencial evasão no nível superior dependem e perpassam uma alteração de paradigma na definição dos gastos públicos brasileiros. Essa mudança demanda por um Estado que conceba as políticas públicas voltadas à educação e as exigências financeiras delas decorrentes como investimentos estratégicos em vez de simples despesa corrente (Cortez et al., 2017). Afinal, não existe universidade, nem curso superior ou potencial evasão e permanência no meio acadêmico, se os estudantes brasileiros não contarem com condições satisfatórias para pertencer e se manter nas instituições de ensino superior, sejam eles trabalhadores ou não.

Tabela 2

Variáveis e focos de intervenção frente à potencial evasão de estudantes trabalhadores e não trabalhadores

\begin{tabular}{|c|c|c|c|c|}
\hline \multirow{2}{*}{$\begin{array}{l}\text { Motivos para } \\
\text { Potencial Evasão }\end{array}$} & \multicolumn{2}{|r|}{ Trabalhadores } & \multicolumn{2}{|r|}{ Não trabalhadores } \\
\hline & Variáveis & Focos de Intervenção & Variáveis & Focos de Intervenção \\
\hline \multirow{2}{*}{ Institucionais } & \multirow{2}{*}{$\begin{array}{l}\text { Nível de } \\
\text { satisfação com } \\
\text { o curso }\end{array}$} & \multirow{2}{*}{$\begin{array}{l}\text { Aprimorar aspectos associados à } \\
\text { qualidade do curso oferecido }\end{array}$} & $\begin{array}{l}\text { Nível de satisfação } \\
\text { com o curso }\end{array}$ & \multirow{2}{*}{$\begin{array}{l}\text { Aprimorar aspectos associados à qualidade } \\
\text { do curso oferecido e ofertar condições } \\
\text { facilitadas de pagamento e financiamento dos } \\
\text { cursos aos estudantes }\end{array}$} \\
\hline & & & $\begin{array}{l}\text { Nível de satisfação } \\
\text { financeira }\end{array}$ & \\
\hline \multirow[t]{2}{*}{ Vocacionais } & \multirow{2}{*}{$\begin{array}{l}\text { Satisfação } \\
\text { com a escolha } \\
\text { profissional }\end{array}$} & \multirow{2}{*}{$\begin{array}{l}\text { Orientação profissional anterior ao } \\
\text { ingresso no ensino superior }\end{array}$} & $\begin{array}{l}\text { Satisfação } \\
\text { com a escolha } \\
\text { profissional }\end{array}$ & \multirow{2}{*}{$\begin{array}{l}\text { Orientação profissional anterior ao ingresso } \\
\text { no ensino superior e entrada em cursos em } \\
\text { que os interesses vocacionais dos estudantes } \\
\text { sejam resguardados, tal como acontece em } \\
\text { instituições particulares devido à menor } \\
\text { concorrência em processos seletivos }\end{array}$} \\
\hline & & & $\begin{array}{l}\text { Instituição } \\
\text { particular }\end{array}$ & \\
\hline \multirow[t]{2}{*}{ Falta de Suporte } & $\begin{array}{l}\text { Dificuldades no } \\
\text { financiamento } \\
\text { próprio }\end{array}$ & \multirow{2}{*}{$\begin{array}{l}\text { Gratuidade do ensino público e linhas } \\
\text { de financiamento e subsídio do ensino } \\
\text { superior que apoiem o estudante a se } \\
\text { inserir e desempenhar adequadamente } \\
\text { no nível superior }\end{array}$} & \multirow[t]{2}{*}{$\begin{array}{l}\text { Insatisfação } \\
\text { financeira }\end{array}$} & \multirow{2}{*}{$\begin{array}{l}\text { Oferecer condições facilitadas de pagamento } \\
\text { e financiamento dos cursos aos estudantes, } \\
\text { familiares e terceiros que se prestem ao } \\
\text { financiamento estudantil }\end{array}$} \\
\hline & Autoavaliação & & & \\
\hline \multirow[b]{2}{*}{ Carreira } & $\begin{array}{l}\text { Instituição } \\
\text { particular }\end{array}$ & \multirow{2}{*}{$\begin{array}{l}\text { Maior relação entre as atividades } \\
\text { acadêmicas e futuro exercício } \\
\text { profissional, tal como proposto } \\
\text { em instituições particulares, além } \\
\text { de maior aplicação do conteúdo } \\
\text { ao contexto profissional em que o } \\
\text { estudante trabalhador se insere para } \\
\text { que haja maior satisfação com a } \\
\text { escolha profissional }\end{array}$} & $\begin{array}{l}\text { Instituição } \\
\text { particular }\end{array}$ & \multirow{2}{*}{$\begin{array}{l}\text { Maior relação entre as atividades acadêmicas } \\
\text { e futuro exercício profissional, tal como } \\
\text { proposto em instituições particulares, } \\
\text { além de condições favoráveis de ensino- } \\
\text { aprendizagem que habilitem o estudante a se } \\
\text { inserir profissionalmente e se satisfazer com } \\
\text { as competências desenvolvidas no curso }\end{array}$} \\
\hline & $\begin{array}{l}\text { Satisfação } \\
\text { com a escolha } \\
\text { profissional }\end{array}$ & & $\begin{array}{l}\text { Satisfação com o } \\
\text { curso }\end{array}$ & \\
\hline Desempenho & Autoavaliação & $\begin{array}{l}\text { Regime de atividades passíveis de } \\
\text { acompanhamento e desempenho } \\
\text { satisfatório pelo estudante trabalhador }\end{array}$ & $\begin{array}{l}\text { Instituição } \\
\text { particular }\end{array}$ & $\begin{array}{l}\text { Oferta de condições para recuperação de } \\
\text { notas e desenvolvimento de monitorias } \\
\text { periódicas, tal como proposto em instituições } \\
\text { particulares }\end{array}$ \\
\hline \multirow[b]{2}{*}{ Interpessoais } & \multirow[b]{2}{*}{ Autoavaliação } & \multirow{2}{*}{$\begin{array}{l}\text { Favorecer a maior integração dos } \\
\text { estudantes com dificuldades frente aos } \\
\text { colegas e outros sujeitos com o intuito } \\
\text { de otimizar o desempenho estudantil } \\
\text { pela maior interação com os pares } \\
\text { acadêmicos }\end{array}$} & $\begin{array}{l}\text { Satisfação com o } \\
\text { curso }\end{array}$ & \multirow{2}{*}{$\begin{array}{l}\text { Instruir professores e outros pares } \\
\text { acadêmicos sobre formas de se relacionar } \\
\text { com os alunos para maximizar a satisfação } \\
\text { estudantil frente ao curso, o que inclui } \\
\text { integrar a condição financeira do estudante } \\
\text { no momento para identificar possíveis } \\
\text { dificuldades relacionais desencadeadas por } \\
\text { essa variável }\end{array}$} \\
\hline & & & $\begin{array}{l}\text { Satisfação } \\
\text { financeira }\end{array}$ & \\
\hline Autonomia & Nao se apresent & significativo frente aos preditores analisa & & \\
\hline
\end{tabular}




\section{REFERÊNCIAS}

Aljohani, O. (2016). A comprehensive review of the major studies and theoretical models of student retention in higher education. Higher Education Studies, 6(2), 1-18. https://doi.org/10.5539/ hes.v6n2p1

Almeida, F. P. B., Silva, M. A., Tassigny, M. M., \& Carneiro, T. C. J. (2015). Papel do tutor no combate à evasão na EAD: percepções de profissionais de uma instituição de ensino superior. Educação, Ciência e Cultura, 20(1), 85-102. https:// doi.org/10.18316/2236-6377.15.5

Amaral, D. P, \& Oliveira, F. B. (2011). O PROUNI e a conclusão do ensino superior: novas trajetórias pessoais e profissionais dos egressos. Ensaio: Avaliação e Políticas Públicas em Educação, 19(73), 861-890. https://doi.org/10.1590/S010440362011000500008

Almeida, L. S. (2007). Transição, adaptação acadêmica e êxito escolar no ensino superior. Revista Galego-Portuguesa de Psicoloxía e Educacion, 15(2), 203-215.

Ambiel, R. A. M. (2015). Construção da Escala de Motivos para Evasão do Ensino Superior. Avaliação Psicológica, 14(1), 41-52. https://doi.or/10.15689/ap.2015.1401.05

Ambiel, R. A. M. (2016). Escala de Motivos para Evasão do Ensino Superior. 1.ed. Hogrefe.

Ambiel, R. A. M., Santos, A. A. A., \& Dalbosco, S. N. P. (2016). Motivos para evasão, vivências acadêmicas e adaptabilidade de carreira em universitários. Psico, 47(4), 288-297. https:// doi.org/10.15448/1980-8623.2016.4.23872

Arruda, A. L. B., \& Gomes, A. M. (2015). Democratização da educação superior: Um estudo sobre a política REUNI. Currículo sem Fronteiras, 15(2), 543-561.

Bacelar-Nicolau, P., Caeiro, S., Martinho, A. P., \& Azeiteiro, U. M. (2015). Attitudes, barriers and motivators as factors for sustainability of higher education e-learning programmes at Universidade Aberta, Portugal. In Integrative Approaches to Sustainable Development at University Level (pp. 567-582). Springer International Publishing.

Baggi, C. A. D. S, \& Lopes, D. A. (2011). Evasão e avaliação institucional no ensino superior: uma discussão bibliográfica. Avaliação: Revista da Avaliação da Educação Superior (Campinas), 16(2), 355-374. https://doi.org/10.1590/S141440772011000200007

Bardagi, M. P., \& Hutz, C. S. (2012). Rotina acadêmica e relação com colegas e professores: impacto na evasão universitária Psico, 43(2), 174-184.

Bardagi, M., \& Hutz, C. S. (2014). Evasão universitária e serviços de apoio ao estudante: uma breve revisão da literatura brasileira. Psicologia Revista. Revista da Faculdade de Ciências Humanas e da Saúde. 14(2), 279-301.

Bisinoto, C., \& Marinho-Araujo, C. (2014). Sucesso acadêmico na educação superior: Contribuições da Psicologia Escolar. Revista E-Psi, 4(1), 28-46.

Boatman, A., \& Long, B. T. (2016). Does Financial Aid Impact College Student Engagement? Research in Higher Education, 57(6), 653-681. https://doi.org/10.1007/s11162-015-9402-y

Borges, A. (2017). Os novos horizontes de exploração do trabalho, de precariedade e de desproteção. Cadernos do CEAS: Revista Crítica de Humanidades, 239(1), 713-741. https://doi org/10.25247/2447-861X.2016.n239

Braveman, P. A., Cubbin, C., Egerter, S., Chideya, S., Marchi, K. S., Metzler, M., \& Posner, S. (2005). Socioeconomic status in health research: one size does not fit all. Jama, 294(22), 28792888. https://doi.org/10.1001/jama.294.22.2879

Cardak, B. A., \& Vecci, J. (2015). Graduates, dropouts and slow finishers: the effects of credit constraints on university outcomes. Oxford Bulletin of Economics and Statistics. 78(3), 323-346. https://doi.org/10.1111/obes.12119
Carmo, E. F., Chagas, J. A. S., Figueiredo, D. B., \& Rocha, E. C. (2014). Políticas públicas de democratização do acesso ao ensino superior e estrutura básica de formação no ensino médio regular. Revista Brasileira de Estudos Pedagógicos, 95 (240), 304-327.

Carvalho, C. H. A. (2006). O PROUNI no governo Lula e o jogo político em torno do acesso ao ensino superior. Educação \& Sociedade, 27(96), 979-1000. https://doi.org/10.1590/S010173302006000300016

Cassundé, F. R. S. A., Lima, A. J. A., Rodrigues, C. V., Quirino, C. A. S. \& Maia, L. G. (2015). O que vou ser quando crescer? A Relação Entre a Atividade Profissional e a Perspectiva de Atuação após o fim do Curso de Graduação. Id on Line Revista Multidisciplinar e de Psicologia 9(26), 190-202. https://doi. org/10.14295/idonline.v9i26.336

CNS - Conselho Nacional de Saúde. (2016). Resolução $N^{o}$ 510/2016. http://conselho.saude.gov.br/resolucoes/2016/ Reso510.pdf

Correia, J. D. O. A. (2017). A precarização das relações de trabalho em virtude da crise econômica em face dos direitos fundamentais dos trabalhadores. Revista do TRT 10, 20(2), 49-54.

Cortez, P. A, Souza, M. V. R., Amaral, M. V. R., \& Silva, L. C. A. (2017). A saúde docente no trabalho: apontamentos a partir da literatura recente. Cadernos Saúde Coletiva, 25(1), 113-122. https://doi.org/10.1590/1414-462X201700010001

Croxton, R. A. (2014). The Role of Interactivity in Student Satisfaction and Persistence In Online Learning. Journal of Online Learning and Teaching, 10(2), 314.

Cunha, J. V. A., Luca, M. M. M., Lima, G. A. S. F., Cornacchione, E. B., \& Ott, E. (2015). Quem está ficando para trás? Uma década de evasão nos cursos brasileiros de graduação em Administração de Empresas e Ciências Contábeis. Revista de Educação e Pesquisa em Contabilidade, 9(2), 124-142. https:// doi.org/10.17524/repec.v9i2.1141

D’Lima, G. M., Winsler, A., \& Kitsantas, A. (2014). Ethnic and gender differences in first-year college students' goal orientation, self-efficacy, and extrinsic and intrinsic motivation. The Journal of Educational Research, 107(5), 341-356. https:// doi.org/10.1080/00220671.2013.823366

Duque, L. C. (2014). A framework for analysing higher education performance: students' satisfaction, perceived learning outcomes, and dropout intentions. Total Quality Management \& Business Excellence, 25(1-2), 1-21. https://doi.org/10.1080 $/ 14783363.2013 .807677$

Duque, L. C., Duque, J. C., \& Suriñach, J. (2013). Learning outcomes and dropout intentions: an analytical model for Spanish universities. Educational Studies, 39(3), 261-284. https://doi.org/10.1080/03055698.2012.724353

Eicher, V., Staerklé, C., \& Clémence, A. (2014). I want to quit education: A longitudinal study of stress and optimism as predictors of school dropout intention. Journal of Adolescence, 37(7), 1021-1030. https://doi.org/10.1016/j. adolescence.2014.07.007

Fávero, P., \& Fávero, L. P. (2016). Análise de dados: modelos de regressão com Excel, Stata e SPSS. Elsevier.

Gairín, J., Triado, X. M., Feixas, M., Figuera, P., Aparicio-Chueca, P., \& Torrado, M. (2014). Student dropout rates in Catalan universities: profile and motives for disengagement. Quality in Higher Education, 20(2), 165-182. https://doi.org/10.1080 $/ 13538322.2014 .925230$

Gomes, A. M, \& Moraes, K. N. (2012). Educação superior no Brasil contemporâneo: transição para um sistema de massa. Educação \& Sociedade, 33(118), 171-190. https://doi.org/10.1590/ S0101-73302012000100011 
Graf, L. P., \& Diogo, M. F. (2009). Projeções juvenis: visões ocupacionais e marcas de gênero. Revista Brasileira de Orientação Profissional, 10(1), 71-82.

Guttman, L. (1945). A basis for analyzing test-retest reliability. Psychometrika, 10(4), 255-282. https://doi.org/10.1007/ BF02288892

Hagenauer, G., \& Volet, S. E. (2014). Teacher-student relationship at university: an important yet under-researched field. Oxford Review of Education, 40(3), 370-388. https://doi.org/10.1080 /03054985.2014.921613

Hair, J. F., Black, W. C., Babin, B. J., Anderson, R. E., \& Tatham, R. L. (2009). Análise multivariada de dados. Bookman Editora.

Heublein, U. (2014). Student drop-out from german higher education institutions. European Journal of Education, 49(4), 497-513. https://doi.org/10.1111/ejed.12097

INEP - Instituto Nacional de Estudos e Pesquisas Educacionais Anísio Teixeira. (2000). Evolução do Ensino Superior Graduação 1980-1998. INEP.

INEP - Instituto Nacional de Estudos e Pesquisas Educacionais Anísio Teixeira. (2015). Resumo Técnico Censo da Educação Superior 2013. INEP.

Jorgensen, S., Fichten, C. S., \& Havel, A. (2012). Are students who are satisfied with their college experience more likely to be retained? Pedagogie Collégiagle, 25(4), 1-7.

Mancebo, D., Vale, A. A., \& Martins, T. B. (2015). Políticas de expansão da educação superior no Brasil 1995-2010. Revista Brasileira de Educação, 20(60), 31-50. https://doi.org/10.1590/ S1413-24782015206003

McKinney, L., \& Burridge, A. B. (2015). Helping or hindering? The effects of loans on community college student persistence. Research in Higher Education, 56(4), 299-324. https://doi. org/10.1007/s11162-014-9349-4

MEC - Ministério da Educação (2015). Relatório de gestão consolidado exercício de 2014. Brasília - DF. http://portal. mec.gov.br/sesu-secretaria-de-educacao-superior/programase-acoes

Miles, J., \& Shelvin, M. (2001). Applying regression \& correlation: A guide for students and researchers. Sage Publications.

Oliveira, R. D. (2018). Secondary Education, work and young people. Educar em Revista, 34(67), 177-197. https://doi. org/10.1590/0104-4060.52751

Pasquali, L. (2015). Delineamento de Pesquisa em Ciência: Fundamentos estatísticos da pesquisa cientifica. Vetor.

Queiroz, F. C. B. P., Queiroz, J. V., Vasconcelos, N. V. C., Furukava, M., Hékis, H. R., \& Pereira, F. A. B. (2013). Transformações no ensino superior brasileiro: análise das Instituições Privadas de Ensino Superior no compasso com as políticas de Estado. Ensaio: Avaliação e Políticas Públicas em Educação, 21(79), 349-370. https://doi.org/10.1590/S0104-40362013000200009

Ribeiro, M. A. (2005). O projeto profissional familiar como determinante da evasão universitária: um estudo preliminar. Revista Brasileira de Orientação Profissional, 6(2), 55-70.

Rodríguez-Gómez, D., Feixas, M., Gairín, J., \& Muñoz, J. L. (2015). Understanding Catalan university dropout from a cross-national approach. Studies in Higher Education, 40(4), 690-703. https://doi.org/10.1080/03075079.2013.842966

Santos, A. S., Oliveira, C. T., \& Dias, A. C. G. (2015). Características das relações dos universitários e seus pares: implicações na adaptação acadêmica. Revista Psicologia: Teoria e Prática, 17(1), 150-163. https://doi.org/0.15348/1980-6906/psicologia. v17n1p150-163
Schlesinger, W., Cervera, A., \& Pérez-Cabañero, C. (2016). Sticking with your university: the importance of satisfaction, trust, image, and shared values. Studies in Higher Education, 1-17. https://doi.org/10.1080/03075079.2015.1136613

Sehnem, S. B., \& Campos, C. A. (2015). "Não era aquilo que eu queria...": Um estudo com universitários que vivenciaram a re-escolha de curso. Pesquisa em Psicologia Anais Eletrônicos, 2(1), 131-142.

SEMESP - Sindicato das Mantenedoras de Ensino Superior (2016). Mapa do Ensino Superior no Brasil. SEMESP.

Sguissardi, V. (2005). Universidade pública estatal: entre o público e o privado/mercantil. Educação \& Sociedade, 26(90), 191-222. https://doi.org/10.1590/S0101-73302005000100009

Silva, A. M., \& Sauaia, A. C. A. (2014). Evasão e qualidade em instituições de ensino superior privadas: uma análise da economia dos custos de transação. Administração: Ensino e Pesquisa, 15(4), 805-830. Recuperado de https://raep. emnuvens.com.br/raep/article/view/5/4

Silva, C. S. C. D., \& Teixeira, M. A. P. (2013). Experiências de Estágio: Contribuições para a Transição UniversidadeTrabalho. Paidéia (Ribeirão Preto), 23(54), 103-112. https:// doi.org/10.1590/1982-43272354201312

Silva, G. P. (2013). Análise de evasão no ensino superior: uma proposta de diagnóstico de seus determinantes. Avaliação: Revista da Avaliação da Educação Superior, 18(2), 311-334. https://doi.org/10.1590/S1414-40772013000200005

Silva, R. L. L., Motejunas, P. R., Hipólito, O., \& Lobo, M. B. C. M. (2007). A evasão no ensino superior brasileiro. Cadernos de Pesquisa, 37(132), 641-659. https://doi.org/10.1590/S010015742007000300007

Sneyers, E., \& De'Witte, K. (2017). The effect of an academic dismissal policy on dropout, graduation rates and student satisfaction. Evidence from the Netherlands. Studies in Higher Education, 42(2), 354-389. https://doi.org/10.1080/03075079 .2015 .1049143

Souza, C. T., Silva, C., \& Gessinger, R. M. (2016). Um estudo sobre evasão no ensino superior do Brasil nos últimos dez anos. CLABES 1(1), 111-118.

Spady, W. G. (1970). Dropouts from higher education: An interdisciplinary review and synthesis. Interchange, 1(1), 6485. https://doi.org/10.1007/BF02214313

Stinebrickner, R., \& Stinebrickner, T. (2014). Academic performance and college dropout: Using longitudinal expectations data to estimate a learning model. Journal of Labor Economics, 32(3), 601-644. https://doi.org/10.1086/675308

Strahan, S., \& Credé, M. (2015). Satisfaction with college: Reexamining its structure and its relationships with the intent to remain in college and academic performance. Journal of College Student Retention: Research, Theory \& Practice, 16(4), 537-561. https://doi.org/10.2190/CS.16.4.d

Tinto, V.(1975). Dropout from higher education:Atheoretical synthesis of recent research. Review of Educational Research, 45(1), 89125. https://doi.org/10.3102/00346543045001089

Zago, N. (2006). Do acesso à permanência no ensino superior: percursos de estudantes universitários de camadas populares. Revista Brasileira de Educação, 11(32), 226-237. https://doi. org/10.1590/S1413-24782006000200003

Zago, N., Paixão, L. P., \& Pereira, T. I. (2016). Acesso e permanência no ensino superior: problematizando a evasão em uma nova universidade federal. Educação em Foco, 19(27), 145-169. https://doi.org/10.24934/eef.v19i27.1334 